\title{
A percepção do assistente social acerca do racismo institucional
}

\section{The social worker's perception of the institutional racism}

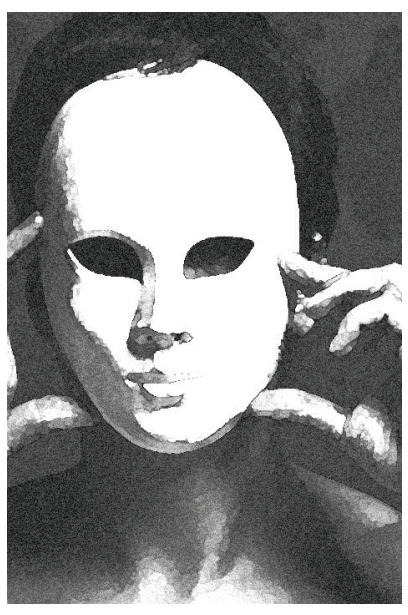

Márcia Campos Eurico*

Resumo: A complexidade das relações raciais no Brasil revela o campo de disputas em que o Serviço Social é chamado a intervir, pois o projeto ético-político que orienta o trabalho profissional do assistente social é portador de uma direção social na perspectiva da emancipação dos sujeitos coletivos. O presente trabalho é resultado da pesquisa e da reflexão sobre o racismo institucional e o trabalho do assistente social. Busca-se investigar a percepção dos profissionais acerca do racismo, do preconceito e da discriminação racial no seu trabalho cotidiano.

Palavras-chave: Racismo institucional. Ética profissional. Questão racial. Serviço Social.

\begin{abstract}
The complexity of the racial relationships in Brazil reveals the battle field in which the social service is called out to intervene, because the ethical-political project that guides social worker's professional work is bearer of a social management in the perspective of the collective fellows' emancipation. The present work is a result of the research and reflection on the institutional racism and social worker's duty. It seeks to investigate professionals' perception concerning the racism, prejudice and the racial discrimination in their everyday work.
\end{abstract}

Keywords: Institutional racism. Professional ethic. Racial matter. Social Service.

* Mestre em Serviço Social pela Pontifícia Universidade Católica de São Paulo - PUC/SP, Brasil; assistente social na Secretaria Municipal de Saúde de São Paulo; docente do Curso de Serviço Social na Universidade Guarulhos _ UNG. E-mail: meurico@ig.com.br. 


\section{Introdução}

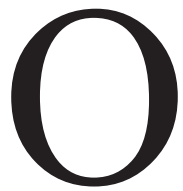

presente artigo é um desdobramento da minha dissertação de mestrado e propõe uma reflexão sobre o racismo institucional e o trabalho do assistente social. Partimos do pressuposto de que a forma como as instituições públicas estão estruturadas pode reforçar o racismo contra amplas parcelas da população, em virtude de sua origem étnico-racial.

Uma das hipóteses é que o trabalho do assistente social sofre interferências do racismo institucional, que fortalece a naturalização e a culpabilização da população negra por sua permanência majoritária nas camadas mais vulneráveis da sociedade, dificultando a proposição de ações que modifiquem essa realidade racialmente fundada.

Para aprofundar o debate, busca-se investigar quais as percepções do assistente social acerca da questão racial, dos desdobramentos das ações institucionais no cotidiano da população negra e que mecanismos podem ser utilizados no sentido de modificar tais relações sociais.

O caminho metodológico estruturou-se a partir da pesquisa qualitativa em virtude do potencial de apreensão crítica da realidade. Os significados atribuídos pelos sujeitos a sua experiência social cotidiana permitem um desvelamento maior das relações raciais e dos mecanismos de dominação/exclusão inerentes à sociedade capitalista.

As informações coletadas por meio de entrevistas abertas permitiram aos sujeitos explicitar suas percepções acerca do racismo e da discriminação racial no cotidiano profissional. A pesquisa permitiu a análise do trabalho profissional a partir da vivência de quatro assistentes sociais, intencionalmente escolhidos(as), ${ }^{1}$ cujos trabalhos são desenvolvidos nas áreas do Judiciário ou da Saúde.

A opção por essas áreas justifica-se pela relevância das pesquisas ${ }^{2}$ que apontam o pertencimento étnico-racial como fator de acesso desigual às políticas públicas ou determinante nas situações de maior probabilidade de adoecimento e/ou

1. "A representatividade do grupo na fala do indivíduo, portanto, ocorre porque tanto o comportamento social como o individual obedece a modelos culturais interiorizados, ainda que as expressões pessoais apresentem sempre variações em conflito com as tradições" (Minayo, 2002, p. 208).

2. Waiselfisz (2011), IBGE, política nacional de saúde integral da população negra (2007), Lopes e Quintiliano (2007), Theodoro (2008). 
morte em certas circunstâncias, de sofrer violência física e/ou psicológica e de discriminação racial.

\section{O Serviço Social e o debate sobre a questão racial}

Nas primeiras décadas do século XX o modo de produção capitalista modifica radicalmente as relações sociais, e a questão social ${ }^{3}$ ganha visibilidade no cenário nacional, a partir das diversas lutas protagonizadas pela classe trabalhadora na defesa dos direitos sociais e contra o autoritarismo do Estado burguês.

O sistema capitalista modifica profundamente a dinâmica das relações sociais, mesmo quando se considera que a desigualdade entre as várias camadas sociais é um fenômeno antigo. A forma que a pobreza assume nessa sociedade é radicalmente nova. Pela primeira vez na história da humanidade, a pobreza cresce na mesma proporção que se criam as condições para sua redução e, no limite, para sua supressão (Netto, 2005).

No bojo desta contradição e sob a influência da Igreja católica, surge na década de 1930 o Serviço Social brasileiro para intervir nas diversas manifestações da questão social, produzidas pela sociedade capitalista.

À medida que o Serviço Social surge profundamente marcado pelo caráter de apostolado católico, analisando a questão social como problema moral e religioso, as relações raciais não são problematizadas adequadamente, uma vez que as reflexões da categoria privilegiam as ações direcionadas à "resolução" moral das contradições de classe.

Várias modificações e determinações sócio-históricas consolidam um Serviço Social maduro, na década de 1980, entre elas a incorporação de uma análise crítica orientada pela herança marxista que permite uma apreensão do movimento de transformação da realidade social.

3. "O Serviço Social tem na questão social a base de sua fundação como especialização do trabalho. Questão social apreendida como o conjunto das expressões das desigualdades da sociedade capitalista madura, que tem uma raiz comum: a produção social é cada vez mais coletiva, o trabalho torna-se mais amplamente social, enquanto a apropriação dos seus frutos mantém-se privada, monopolizada por uma parte da sociedade... a produção fruto de um trabalho cada vez mais coletivo, contrastando com a desigual distribuição da riqueza entre grupos e classes sociais nos vários países, o que sofre a decisiva interferência da ação do Estado e dos governos" (Iamamoto, 1999, p. 27). 
No interior desse processo são criadas as condições para a compreensão teórico-metodológica do significado do Serviço Social no processo de produção e reprodução das relações sociais, desvelando o seu caráter político, ou seja, o fato de que não há neutralidade no trabalho do assistente social.

O Código de Ética Profissional do Assistente Social, aprovado em 1993, é o primeiro código profissional do Serviço Social que introduz a questão da não discriminação como um de seus princípios fundamentais. Isso remete a uma reflexão acerca da importância atribuída à ética e aos direitos humanos no interior do projeto ético-político a partir dos anos 1990, fortalecendo as bases para o desenvolvimento de um debate sobre a questão étnico/racial no cotidiano do assistente social.

Nesse cenário e apesar das crescentes reivindicações do movimento negro, em defesa de uma ressignificação da questão racial no Brasil, a contribuição da profissão na produção do conhecimento acerca dessa temática permanece muito tímida.

Se a aproximação do Serviço Social em direção ao debate étnico-racial é tímida, há que se problematizar como a profissão vem desvelando os discursos e conceitos sobre essa temática.

Ao se deparar com os vocábulos afrodescendente, branquitude, discriminação racial, etnia, negro, preconceito racial, racismo, racialismo e raça, os profissionais podem transitar por diversas interpretações, muitas vezes antagônicas. Entendemos que as palavras são carregadas de significados e, portanto, optamos por explanar sucintamente que sentido atribuímos aos conceitos intrínsecos à questão racial nesta pesquisa.

A análise das principais bibliografias ${ }^{4}$ sobre as relações raciais no Brasil revela uma diversidade de conceitos, que ora podem reforçar o posicionamento político a favor da erradicação do racismo e da discriminação racial, ora podem fortalecer o discurso dominante na perspectiva da manutenção do status quo.

Diversos cientistas sociais utilizam, em geral, o padrão de relações raciais dos Estados Unidos da América para comparar, contrastar e entender a construção social das raças em outros países e especialmente no Brasil. Ao identificar que o modelo americano, conhecido como "Jim Crow", exibia um padrão de relações violento,

4. Para que o leitor possa aprofundar o estudo sobre as relações raciais sugerimos consultar as principais obras comentadas e organizadas por Cuti e Fernandes no livro Consciência negra do Brasil: os principais livros (2002). 
conflitivo e segregacionista contra os negros, respaldado em regras precisas de filiação grupal, diversos pesquisadores negaram e negam a existência do racismo no Brasil.

Na história contada sobre o país há uma lacuna importante quanto ao destino da população negra após a abolição, fruto do silêncio que insiste em ratificar que a injustiça cometida contra essa parcela da população cessou com o fim da escravatura. Por outro lado, a busca pela transformação da nação em um país desenvolvido e industrializado logrou justificar essa exclusão, e os estereótipos ${ }^{5}$ se disseminaram pelo país, atribuindo ao negro a culpa por sua condição social.

A atribuição de cor aos indivíduos, prática comum no Brasil e que fundamenta a construção de grupos de cor pelos sociólogos, longe de prescindir da noção de "raça", pressupõe uma ideologia racial e um racismo muito peculiares. (Guimarães, 1999, p. 20)

Qualquer estudo sobre o racismo no Brasil deve partir do princípio de que aqui o racismo é um tabu, pois os brasileiros se imaginam numa democracia racial. Essa ideia de civilidade tem raízes profundas na história do Brasil e pode ser verificada desde que foi abolida a escravidão (Guimarães, 1999).

De acordo com Guimarães (1999), o racismo ocorre quando grupos humanos considerados raças ou identificados por traços raciais ou racializados (como, por exemplo, a cor) são tratados de modo desigual do ponto de vista econômico, político, social e cultural.

As desigualdades são entendidas como discriminação racial quando se encontram e se comprovam mecanismos causais que operam na esfera individual e social e que possam ser retraçados ou reduzidos à ideia de raça. Assim, grupos considerados superiores obtêm privilégios em relação aos outros grupos, considerados inferiores.

A discriminação racial materializa o preconceito racial que é a manifestação comportamental baseada no juízo de valor, socialmente construído e destituído de base objetiva.

5. Estereótipo: trata-se de uma generalização excessiva a respeito do comportamento ou de outras características de membros de determinados grupos sociais. Os estereótipos étnicos e raciais podem ser positivos ou negativos, sendo os últimos normalmente mais ressaltados. É importante destacar que mesmo os ostensivamente positivos podem comumente remeter a uma avaliação negativa, conforme Cashmore et al. (2000). 
O preconceito pode ser individual ou social. O homem pode estar tão cheio de preconceitos com relação a uma pessoa ou instituição concreta que não lhe faça absolutamente falta a fonte social do conteúdo do preconceito... Costumamos, pura e simplesmente, assimilá-los de nosso ambiente, para depois aplicá-los espontaneamente a casos concretos através de mediações. (Heller, 1970, p. 49)

O racismo no Brasil, enquanto uma construção sócio-histórica, traz consigo o preconceito e a discriminação racial, acarretando prejuízos à população negra nas diferentes fases do ciclo de vida, independente da camada social e da região de moradia. Reforça-se pela linguagem comum, mantém-se e alimenta-se pela tradição e pela cultura, ao mesmo tempo em que influencia a vida, a forma como as instituições se organizam e as relações interpessoais (Lopes e Quintiliano, 2007).

A utilização do conceito de raça nas Ciências Sociais e na política brasileira apresenta vários problemas que precisam ser equacionados. Este não está baseado na fundamentação biológica, mas porta um significado propriamente sociológico, relacionado a determinada identidade cultural. "Trata-se de um sistema de marcas físicas (percebidas como indeléveis e hereditárias), ao qual se associa uma 'essência', que consiste em valores morais, intelectuais e culturais" (Guimarães, 1999, p. 28).

O Brasil constrói uma noção particular de raça segundo a qual podem ser “consideradas" brancas as pessoas mestiças e de pele mais claras que exibem símbolos da europeidade: formação cristã e domínio das letras. Por essa regra, quanto mais próxima a pigmentação da pele estiver do branco europeu, maior a aceitação social e a valorização da pessoa (Guimarães, 1999).

A opção teórica pelo conceito de raça justifica-se pelo modo como o racismo opera no Brasil. Portanto, sua utilização não remete ao sentido clássico, relativo às categorias biológicas. Nessa perspectiva, concordamos com Ianni (1992, p. 120):

As raças são categorias históricas, transitórias, que se constituem socialmente a partir das relações sociais: na fazenda, engenho, estância, seringal, fábrica, escritório, escola, família, igreja, quartel, estradas, ruas, avenidas, praças, campos e construções. Entram em linha de conta caracteres fenotípicos. Mas os traços raciais visíveis, fenotípicos, são trabalhados, construídos ou transformados na trama de relações sociais.

É na esfera das relações sociais que a questão racial ganha amplitude, na forma como a população negra acessa a riqueza socialmente produzida, ao estabelecer relações afetivas, no acesso e permanência no mercado de trabalho, na 
invisibilidade escolar. Enfim, é na vida cotidiana que a diversidade racial ganha contornos de desigualdade social.

Por sua vez, o conceito de etnia refere-se a indivíduos que compartilham uma herança social e cultural transmitida de geração em geração. Etnia refere-se a aspectos culturais e também tem um sentido político, de afirmação da diferença cultural enquanto valorização humana. Pessoas que podem ser identificadas como pertencentes a grupos raciais distintos, podem ser agrupadas num mesmo grupo étnico e vice-versa. Para além das características físicas, há um resgate do pertencimento ancestral, de um passado comum, conforme descrição a seguir:

Um grupo possuidor de algum grau de coerência e solidariedade, composto por pessoas conscientes, ao menos em forma latente, de terem origens e interesses comuns. Um grupo étnico não é mero agrupamento de pessoas ou um setor da população, mas uma agregação consciente de pessoas unidas ou proximamente relacionadas por experiências compartilhadas. (Cashmore et al., 2000, p. 196)

Do exposto, pode-se inferir que os conceitos raça e etnia não são sinônimos, mas complementares, razão pela qual nas diversas produções é comum encontrarmos a associação raça/etnia. Entendemos que raça continua atual e que os aspectos culturais abarcados pelo termo etnia são motivadores de discriminação, principalmente quando associados à raça. Logo, optamos por problematizar a questão racial a partir da discussão de raça/etnia.

O termo negro, por sua vez, para além da cor da pele, remete a uma origem racial, aos descendentes de negros africanos no Brasil, valorizando os atributos físicos e culturais daqueles que representam quase metade da população brasileira. O termo tem um sentido político, de sujeitos que constroem a história, ao mesmo tempo em que se constroem (Gomes, 1995). Negro é uma categoria utilizada pelo movimento negro para reforçar a identidade, em que preto e pardo são apenas cores, enquanto negra seria a raça, em sua dimensão social.

Consideramos importante também nomear a brancura, categoria socialmente construída, que começou a ser utilizada na segunda metade do século XVII e significava superioridade e privilégio, em contrapartida aos não brancos, considerados “os outros", conforme Cashmore et al. (2000). Na atualidade, a brancura confere vantagens e prestígios, reatualizando o racismo nas relações sociais.

A ideologia da brancura permitiu a construção/consolidação de relações sociais profundamente desiguais, com a atribuição de privilégios numa sociedade patriarcal, 
sexista e racista. A análise da questão racial neste trabalho não pode estar dissociada da análise da ideologia da brancura, pois é no âmbito das relações sociais que esses grupos disputam poder, espaço e território.

Branquitude - Na prática, ser branco exige pele clara, feições européias, cabelo liso; ser branco no Brasil é uma função social e implica desempenhar um papel que carrega em si uma certa autoridade ou respeito automático, permitindo trânsito, eliminando barreiras. Ser branco não exclui "ter sangue negro" ou indígena. (Iraci e Sovik, 2004, p. 19)

Para efeitos metodológicos consideramos importante destacar também os conceitos de afro-brasileiro:

Afro-brasileiro surge entre 1930 e 1940, em linhas de pensamento distintas das atuais. Além de que, afro-brasileiro faz parte de um período no qual os grupos de intelectuais brasileiros eram totalmente desinformados, para não dizer ignorantes, sobre a história africana. Nutriam teorias racistas sobre a cultura de base africana. Vejam que, nesta época, Gilberto Freyre e os seus seguidores consideravam a cultura africana inferior à européia. (Cunha Jr., apud Romão, 2005, p. 253)

E afrodescendente, em que pese a opção de não utilizá-los na nossa fundamentação teórica, significa que: "O pleno conhecimento do passado africano, nasce sobretudo em decorrência deste conhecimento e da necessidade de relacionar o passado africano com a história do Brasil.” (Cunha Jr., apud Romão, 2005, p. 253).

Na perspectiva de fortalecer o debate sobre a questão racial, optamos por não utilizar o termo afrodescendente, ainda que tenha seus méritos, pois na atualidade tem conotações ambíguas. Se partirmos da premissa, verdadeira, de que os negros africanos têm presença marcante na formação da sociedade brasileira, uma parcela importante da nossa população atualmente é afrodescendente.

Por outro lado, essa mesma parcela da população pode no cotidiano, pelos diversos motivos apresentados ao longo desta reflexão, ocultar sua origem ancestral, enfraquecendo o debate político sobre a questão racial no Brasil.

As pessoas não são discriminadas apenas pela sua descendência, mas pelo fenótipo - cor da pele, traços faciais, tipo de cabelo - , pelo externo, no momento em que acessam o mercado de trabalho, os serviços públicos, os espaços coletivos etc. 
Assim, entendemos que afrodescendente é uma categoria extremamente perigosa, que pode fortalecer o discurso daqueles que insistem em afirmar que somos todos brasileiros, desconsiderando a diversidade e a perversidade das relações sociais, terreno em que a discussão sobre a questão racial não tem base de sustentação.

A realidade brasileira em sua face mais perversa, das desigualdades sociais decorrentes da origem racial, tem sido questionada e fortemente combatida por diversos setores da sociedade, que ampliaram o debate público sobre a questão racial e intensificaram na última década as discussões sobre como o setor público poderia comprometer-se mais efetiva e continuamente com a prevenção e o combate ao racismo e às desigualdades raciais.

O processo é contraditório e exacerba questões que por séculos o país tenta silenciar. A tarefa é árdua, pois o racismo perpassa todas as esferas da vida cotidiana, se reproduz nas instituições e constantemente é naturalizado. A banalização da questão racial atinge inclusive uma parcela importante da população negra que não consegue perceber a trama de relações sociais e se culpabiliza por sua condição social.

O discurso dominante que ainda insiste em desvalorizar a população negra, sua cultura e suas tradições, perde legitimidade à medida que o debate racial avança, desconstruindo estereótipos. Concomitantemente, as diversas mobilizações do Movimento Negro culminaram em medidas como a criminalização do racismo, as políticas afirmativas, a defesa da equidade na educação e na saúde, entre outros direitos sociais.

\section{Racismo institucional: a exacerbação da desigualdade social}

O racismo continua sendo uma implacável e deprimente questão dos nossos tempos. São poucos os temas, se é que há outros, que demandam tanta atenção e esforço com tão poucos frutos. Toda vez que "baixamos a guarda", uma nova descoberta revela a complexidade, a virulência e a absoluta obstinação daquilo que notadamente tornou-se o problema do século XX. (Cashmore et al., 2000, p. 11)

O racismo, por si só, é perverso e desencadeia relações sociais profundamente desumanas e continua a se reproduzir cotidianamente no início do século XXI. Quando ele perpassa o cotidiano das instituições, a situação torna-se ainda mais complexa e cristalizada, configurando-se como racismo institucional. 
O emprego do conceito de discriminação indireta ou racismo institucional para a promoção de políticas de equidade racial já é utilizado desde o final dos anos 1960 em diversos países. Nos Estados Unidos, por exemplo, o conceito surge no contexto da luta pelos direitos civis e com a implementação de políticas de ações afirmativas. $\mathrm{Na}$ Inglaterra, o conceito passa a ser incluído como instrumento para a proposição de políticas públicas na década de 1980, como resultado do crescimento da população não branca e das dificuldades observadas pelo Poder Judiciário em responder às demandas daquela população. No Brasil, a partir de meados dos anos 1990, esse conceito começa a ser apropriado para a formulação de programas e políticas de promoção da equidade racial. (Jacoud, 2008, p. 141)

A necessidade de democratizar o acesso da população negra às políticas públicas exige uma reflexão sobre o conceito de racismo institucional, que nas palavras do DFID/PNUD (2005, p. 6) significa:

Fracasso das instituições e organizações em prover um serviço profissional e adequado às pessoas devido à sua cor, cultura, origem racial ou étnica. Ele se manifesta em normas, práticas e comportamentos discriminatórios adotados no cotidiano do trabalho, os quais são resultantes da ignorância, da falta de atenção, do preconceito ou de estereótipos racistas. Em qualquer caso, o racismo institucional sempre coloca pessoas de grupos raciais ou étnicos discriminados em situação de desvantagem no acesso a benefícios gerados pelo Estado e por demais instituições e organizações.

$\mathrm{O}$ racismo institucional refere-se às operações anônimas de discriminação racial em instituições, profissões ou mesmo em sociedades inteiras (Cashmore et al., 2000). O anonimato existe à medida que o racismo é institucionalizado, perpassa as diversas relações sociais, mas não pode ser atribuído ao indivíduo isoladamente. Ele se expressa no acesso à escola, ao mercado de trabalho, na criação e implantação de políticas públicas que desconsideram as especificidades raciais e na reprodução de práticas discriminatórias arraigadas nas instituições.

Portanto, o racismo institucional possui duas dimensões interdependentes e correlacionadas: a político-programática, e a das relações interpessoais. Quanto à dimensão político-programática podemos dizer que ela compreende as ações que impedem a formulação, implementação e avaliação de políticas públicas eficientes, eficazes e efetivas no combate ao racismo, bem como a visibilidade do racismo nas práticas cotidianas e nas rotinas administrativas. A dimensão das relações 
interpessoais abrange as relações estabelecidas entre gestores e trabalhadores, entre trabalhadores e trabalhadores, entre trabalhador e usuário, e entre usuário e trabalhador, sempre pautadas em atitudes discriminatórias (Amma-Psique e Negritude Quilombhoje, 2008).

No âmbito institucional — no qual se desenvolvem as políticas públicas, os programas e as relações interpessoais —, toda vez que a instituição não oferece acesso qualificado às pessoas em virtude de sua origem étnico-racial, da cor da sua pele ou cultura, o trabalho fica comprometido. Esse comportamento é resultante do racismo institucional (Lopes e Quintiliano, 2007).

Para identificar a parcela da população brasileira que sofre com as manifestações do racismo na vida cotidiana, optamos por utilizar as análises desenvolvidas por Paixão e Carvano (2008) na qualificação dos indicadores sociais das desigualdades raciais no Brasil, publicadas no Relatório anual das desigualdades raciais 2007-2008.

O relatório analisou a evolução dos indicadores sociais dos distintos grupos de cor ou raça e sexo no Brasil. As bases de dados utilizados pelos pesquisadores para compor a análise foram, preferencialmente, as fontes oficiais.

Conforme dados do RDR 2007-2008, a população residente no Brasil, segundo os grupos de cor ou raça, estava distribuída da seguinte forma: em 1995 a população total somava 152.374 .603 habitantes, dos quais 82.826 .798 eram brancos e 68.635.438 eram pretos e pardos; em 2006 totalizava 183.550.526, dividida entre 92.406.621 brancos e 89.726 .595 pretos e pardos; os demais eram de cor ou raça indígena e amarela.

Em 2006, a população branca residente no Brasil era de 49,7\% e a população de pretos e pardos era de $49,5 \%$. Os demais habitantes eram de cor ou raça indígena $(0,3 \%)$ e de cor ou raça amarela $(0,5 \%)$. Quanto à população de cor ou raça preta e parda, sua distribuição relativa entre as regiões geográficas do país ocorre da seguinte forma: a maioria vive majoritariamente no Nordeste, totalizando 39,3\%, seguida pela região Sudeste, com 34,6\% (Paixão e Carvano, 2008).

Ainda que os dados estatísticos sobre o percentual de negros na sociedade brasileira ratifiquem a presença marcante da população negra no país, a sua inserção precária na sociedade de classes nos indaga sobre os mecanismos que impedem sua ascensão social. Estratégias devem ser criadas para a construção de uma nova sociabilidade, combatendo todo tipo de preconceito ou discriminação racial contra esse grupo. 


\section{Desdobramentos da pesquisa}

A análise da pesquisa revelou que a percepção dos assistentes sociais acerca da questão racial e dos mecanismos de reprodução do racismo no interior da sociedade brasileira ainda está bastante distorcida. A desigualdade étnico-racial é percebida por metade das entrevistadas, que conseguem descrever como a forma de ser da instituição, neste caso uma instituição de internação para adolescentes que cometeram ato infracional, interfere no olhar sobre a população negra, carregado de estereótipos.

Os adolescentes vêm de uma camada bem empobrecida da classe trabalhadora, a maioria são negros. Então tem um corte de classe, dos mais desafortunados, e um corte de cor, a maioria é negra. E todos eles se parecem... passam de moletom azul, em fila [para audiência], todos com a cabeça raspada. A identidade do adolescente nós desvelamos no atendimento individual... A pobreza, a forma como é visto, e sua família empobrecida, é como se fosse um estorvo. De alguma forma o Estado precisa conter esses indivíduos e faz a contenção mesmo, porque desqualifica, desagrega o grupo familiar. Ainda existe um estereótipo de que a família estruturada é aquela que tem pai, mãe, filhos e tudo totalmente organizado, sem conflitos. E o agravante é que esses adolescentes sofrem esse tipo de constrangimento porque eles não têm defesa. Embora tenham direito a defensoria, ao advogado público, não são reconhecidos como sujeitos de direito, por serem pobres, por serem negros e porque cometeram um ato infracional. (Ana)

Para onde vai a educação do povo negro, que está super/defasada? A herança cultural? O Brasil caminha para a era da tecnologia, os empregos serão na área da alta tecnologia e a criança negra está sendo gentilmente convidada a sair da escola. Cada dia que passa a educação básica está mais defasada, e quem é excluído da escola basicamente é a população negra... Quanto à condição econômica, eu diria que $97 \%$ é uma marca a questão da pobreza, em uma dimensão mais ampla, incluindo a cultura e tudo mais. Classe média é muito pouco, não fica! Você pode ver que não fica... Esses meninos que não recebem pensão, grande parte passam por aqui. É raro o caso em que a gente pergunta se o pai paga a pensão e a mãe diz paga... A diferença entre a quantidade de processos que entram na Vara da Família e a quantidade de homens que são presos por não pagar pensão é enorme. É um reflexo da sociedade, o homem tem uma proteção maior, ele passa impune, ele burla a justiça, ele não paga pensão. (Vitória)

Quanto à possibilidade de uma formação permanente, de momentos de reflexão sobre o trabalho cotidiano, o universo institucional se delineia como um lugar 
de cerceamento da informação e do debate sobre qualquer temática, incluindo a questão racial.

Todas as profissionais entrevistadas referem participar de reunião semanal para discussão dos casos mais complexos, porém afirmam não haver espaço sistemático de atualização profissional. Por outro lado, quando alguém da equipe tem a possibilidade de participar de debates em espaços fora da instituição, tais como congressos, seminários, colóquios, oficinas, esses conhecimentos não são aplicados no trabalho cotidiano, de forma sistemática.

A análise da fala das entrevistadas permite afirmar que o racismo permanece arraigado em diversas instituições:

Estes três elementos configuram-se na morte social: ser pobre, ser negro e cometer ato infracional, que denotam para a justiça que o indivíduo não tem condições de viver em sociedade. (Ana)

Nós percebemos mais pelo viés econômico, mas é uma coisa gritante. Afinal, são poucos brancos na Fundação Casa. E ouço muitas mães dizerem: "Puxa, mas o outro saiu! Será que porque ele era mais clarinho?". Ainda existe aquele juízo de que o negro é potencialmente perigoso. (Ana)

Quanto ao racismo institucional, a dimensão político-programática permite explicar como o conservadorismo opera no âmbito das ações institucionais, favorecendo a violação de direitos:

Presenciamos violações de direito sempre. Em quase todos os atendimentos nós ficamos inconformados com a internação, porque partimos do princípio de que só a contenção, sem nenhum trabalho (característica da Fundação Casa) é profundamente danosa para o adolescente. Eu já atendi casos de adolescentes que tentaram o suicídio, duas, três vezes, mães que tentaram se enforcar com fio elétrico do chuveiro em razão da internação do filho. Adolescentes que sofrem violência física dentro da instituição, constrangimento moral. Sempre identificamos esse tipo de situação e a violação dos direitos. (Ana)

Se não há o conhecimento histórico da questão racial no Brasil, o adolescente é automaticamente mais punido por isso. Então ele fica mais tempo na instituição mesmo que a infração dele seja menor... Uma mãe sozinha que foi vitimizada na infância, e que hoje é vitimizada de novo e o filho, antes de ser um infrator, foi vítima também. Então as histórias mais escabrosas e a mãe não dá conta das respostas que a instituição "precisa" para liberar o menino. (Vitória) 
E o autoritarismo como justificativa para o restabelecimento da ordem, ainda que a seleção entre aqueles que devem ser punidos ou não, via de regra, se apoie em estereótipos que determinam quem é naturalmente recuperável e quem não tem mais "jeito".

A discussão étnico-racial só aparece quando é para mandar para a cadeia, para internação. Apesar de o Sistema Judiciário apresentar a imagem simbólica de que não vê, não ouve e não fala e que todos são iguais em direitos e deveres, não tem discriminação de cor. Juridicamente sim, do ponto de vista civil sim, mas na efetivação da vida isso não é verdade. Os adolescentes negros sofrem mais e são punidos por serem negros e pobres. (Ana)

E falando disso, o Judiciário não é diferente. Então no processo tem várias formas de abordar e, enquanto assistente social, a gente contribui significativamente para isso quando não consegue perceber que tem uma desigualdade de educação, de moradia, contribui na hora que esse menino é muito mais pobre, fica pouco na escola, a família dele está sempre com o "pé na casca de banana" e ele também. (Vitória)

Consideramos relevante destacar que a percepção da presença do racismo institucional é explicitada pelas duas assistentes sociais que trabalham no Sistema Judiciário. $\mathrm{O}$ que pode ser explicado pela própria natureza do trabalho, com atendimento individual, dos adolescentes que estão em cumprimento de medida por ato infracional.

As assistentes sociais da área da saúde entrevistadas apresentam uma discussão mais abstrata sobre a reprodução de qualquer forma de discriminação racial, ainda que as pesquisas sobre as disparidades no acesso à saúde revelem um quadro de inclusão precária da população negra aos serviços nessa área.

Eu não acho que seja uma coisa fácil, apesar de ser Serviço Social. Até pela identificação dos profissionais com o assunto. Às vezes nem todo mundo está preocupado com isso, pelo fato de não ser negro. "Eu não sou negro, por que eu vou discutir isso?" Por isso que acaba não sendo uma coisa muito ampla. Às vezes o interesse da pessoa não é esse. As pessoas que se identificam mais, a maioria é negra. (Juliana)

Quando se trata de encaminhamentos, de acesso aos recursos existentes nas situações de discriminação racial vivenciadas pela população negra, a situação torna-se ainda mais difícil. A reflexão sobre a essência das demandas apresentadas e o componente étnico-racial que pode estar oculto nesse pedido não é problematizada. 
Eu sei que tem delegacias para pessoas que sofrem discriminações. Se alguém viesse procurar, iria atrás para orientar e encaminhar essa pessoa, porque eu sei que tem. Eu ia procurar na internet ou até mesmo no nosso livro de recursos, no Serviço Social. Eu acredito que no nosso livro de recurso deva ter. Ou ligar na Delegacia da Mulher, pedir informação. (Juliana)

Nunca aconteceu, no tempo que eu estou aqui. Não chegou até mim. Eu falaria que eu ia verificar e depois dar uma resposta, porque eu não saberia. Eu consultaria na internet. No Google, procuraria racismo e os órgãos que cuidam. (Rosângela)

Mesmo trabalhando com crianças, adolescentes e mulheres em situação de violência sexual "Na verdade, dos $100 \%$ de atendimentos, a meu ver $85 \%$ está entre as crianças e os adolescentes, os outros 15\% ficam as mulheres, são muitas crianças." (Juliana), a assistente social afirma que não presenciou até o momento nenhuma violação de direitos.

Quanto à dimensão das relações interpessoais, uma assistente social denuncia as situações de discriminação racial a que é submetida constantemente por parte dos usuários que acessam o Serviço Social daquela instituição.

No Serviço Social somos dez assistentes sociais e duas que podem se considerar negras, mas a outra ainda é mais clarinha. Negra, mesmo, assim, seria eu. Só que eu percebo quando o usuário procura o setor, que tem duas, três que são brancas e eu estou lá no meio, ele nunca vem se dirigir a mim. E às vezes eu estou aqui na frente e ele pede para falar com a assistente social... E alguém responde: "aqui somos todas assistentes sociais", ele passa por mim e vai falar com a outra. É aquela coisa... de achar que assistente social, para ser alguém, tem que ser branca... Às vezes, pelo fato, de ser negra tem esse questionamento se sou assistente social. Tem hora que eu fico até irritada e eu falo: Por quê? Sou assistente social! (Juliana)

Nas relações interpessoais com a equipe técnica, a mesma refere que não há problemas, pois faz parte de uma equipe "legal" e por isso não se sente discriminada pelos colegas de trabalho:

Nas reuniões de equipe não tem psicóloga negra, não tem médica negra, eu sou a única que faço parte dessa mesa de reunião... Quanto ao grupo eu não tenho problema nenhum, meu coordenador é muito legal. Acho que eu já superei, pois, pelo menos, as assistentes sociais que trabalham comigo são muito legais. (Juliana) 
A dimensão das relações interpessoais compreende ainda a reprodução de piadas e comentários racistas, a relação naturalizada entre raça/etnia e violência exacerbada, ainda que em mensagens subliminares.

Ao ser indagada sobre a possível relação entre a questão social e a questão racial no Brasil, a entrevistada tem a resposta pronta, que de antemão culpabiliza o sujeito por sua condição "inferior" e naturaliza a desigualdade racial:

A questão da desigualdade tem uma relação com a questão da cor. No emprego a pessoa negra fazendo o mesmo papel recebe menos, tem oportunidades que não aceitam cor negra. Melhorou, mas ainda tem essa questão. Se uma pessoa negra tem uma condição melhor, isso reduz as possibilidades de ser vítima de racismo, porque ela tem uma conscientização e pode se impor como um cidadão comum... O nível de conhecimento maior, de estar numa posição maior vai trazer menos problemas com relação a cor. Ela se insere melhor no ambiente do que uma pessoa que tem uma baixa renda e é de cor. A falta de autoestima, de conhecimento, porque às vezes 0 próprio negro se sente inferior. Então não é só o ambiente, não é só a sociedade, é ele também que acaba se sentindo inferior. (Rosângela)

Se admitimos que a sociedade reforça esse comportamento, de que forma o racismo pode ser combatido?

É como eu falei, acho que hoje ele vai ser amenizado. Mais para frente, pode ser combatido. Quinhentos anos, o racismo. Depois, dez anos, vinte anos, não sei onde começou a se pensar. É um início, hoje ameniza, mas acho que a tendência é até as políticas daqui para frente, serem cada vez mais de combate ao racismo até chegar ao ponto que as pessoas vão se achar iguais, eu acredito nisso. (Rosângela)

A suposta transformação ancora-se no velho discurso do branqueamento, a partir da miscigenação, muito bem problematizado por Chaui (2007) e reatualizado com vistas à convivência harmoniosa e pacífica entre os sujeitos.

É lento, vai gerar muitas discussões, como já gerou, mas lá para frente... muitos anos lá para frente vai combater. Principalmente porque cada vez mais negros e brancos estão se unindo, e estão nascendo crianças que vão ser... é mestiço que fala... vão nascer crianças, mestiças. (Rosângela)

Este é o caminho? A solução pode ser alcançada com os casamentos interétnicos? 
É de brancos e negros, vai ser tanto, que vai acontecer isso. Uma população praticamente mestiça e vai ter poucos só brancos, poucos só negros e quando chegar nesse ponto, o racismo já vai estar bem superado, porque a maioria vai ser essa população. Eu vi uma pesquisa sobre isso aqui no Brasil, não sei daqui quanto tempo, os brancos vão ser a minoria e vai surgir essa população que é a mistura. Então isso cada vez mais vai facilitar a questão da não discriminação. (Rosângela)

Essa linha de raciocínio se estrutura a partir da ideia de que o problema do racismo no Brasil está relacionado apenas à cor da pele. Nesse sentido é ancorada em supostas pesquisas que comprovam a mudança do perfil racial da população brasileira. E há uma ideia ainda mais perversa e que perpassa o cotidiano da população negra que é a negação da contribuição dos povos africanos para a formação da sociedade brasileira.

Os avanços obtidos com a Lei n. 7.437, conhecida como Lei Caó que inclui, entre as contravenções penais, a prática de atos resultantes de preconceito de raça/ cor; com a Lei n. 10.639, que torna obrigatório, nas escolas de nível fundamental e médio, o ensino de história da África e a contribuição dos povos africanos para a formação do Brasil; e com o Estatuto da Igualdade Racial, não são sequer citados. Há uma completa ignorância quanto aos mecanismos legais que tentam coibir as práticas discriminatórias presentes na sociedade brasileira e que nem de longe serão extintas nos e pelos relacionamentos afetivos.

Pelo contrário, há que se considerar que os casamentos interétnicos requisitam um aprofundamento maior dos sujeitos sobre sua origem, história e trajetória, que possibilitem a formação de novos sujeitos, mais conscientes das múltiplas determinações que constituem o ser social.

\section{À guisa de conclusão}

A pesquisa revelou que o debate sobre a questão racial precisa ser ampliado e sistematicamente discutido pelo conjunto da categoria profissional, mas revelou também a dificuldade dos profissionais em dar concretude ao Código de Ética profissional, pois os seus princípios são citados abstratamente, sem a necessária conexão com a realidade vivenciada pela população negra.

Decerto, pela própria história da profissão e o conservadorismo que marca sua gênese, o debate sobre a questão racial não encontrou terreno fértil para ser incorporado pelo Serviço Social até a década de 1980. 
Entretanto, diante das conquistas históricas do projeto ético-político, expressas eticamente no Código de Ética de 1993, a busca de efetivação dos princípios que norteiam o trabalho do assistente social é um imperativo ético a ser perseguido. O combate ao racismo institucional e à discriminação por questões de raça/etnia se inscreve nessa lógica, e a questão racial pode ser debatida se as concepções teóricas que culminaram naquela construção forem devidamente apropriadas.

A população negra ainda vive, majoritariamente, em situação de vulnerabilidade social, suscetível a mortes violentas, a agressões e abusos de autoridade, bem como invisível, nas suas especificidades, para as ações das políticas públicas, principalmente na área da saúde, educação, assistência social, habitação, nas artes e na mídia.

Há uma dificuldade em trazer à tona a discussão étnico-racial na trama de relações sociais, na sociedade burguesa, profundamente marcada pelo discurso da "democracia racial" e pelo racismo camuflado que também aliena a população negra, bloqueando seus processos de conscientização, participação e organização política (Pinto, 2003).

Quanto ao projeto ético-político do Serviço Social, é pertinente ressaltar que as suas orientações de valor possuem uma objetividade real e dependem também da subjetividade dos sujeitos que o realizam cotidianamente.

Portanto, o trabalho do assistente social compõe-se de múltiplas facetas, e a análise empreendida nessa pesquisa sobre o racismo institucional pode favorecer o desvelamento das práticas discriminatórias enraizadas em diversas instituições, com vistas à garantia dos direitos sociais, sem qualquer forma de discriminação racial.

A investigação das manifestações do racismo institucional na presente pesquisa possibilitou o desvelamento de práticas conservadoras, autoritárias e carregadas de estereótipos no cotidiano profissional.

A pesquisa nos coloca diversos desafios a ser enfrentados, que vão desde o reconhecimento da importância da discussão racial para o Serviço Social; a proposição de ações que efetivem a inclusão do quesito raça/cor nos instrumentais utilizados com a consequente interpretação dos dados; a desconstrução dos estereótipos ainda presentes no discurso profissional que, via de regra, desqualificam a população negra; o exercício da escuta qualificada como um dos caminhos para a reconstrução da trajetória dos sujeitos e para a proposição de alternativas à permanente discriminação racial; e, por fim e sistematicamente, a ampliação do debate sobre a 
questão racial e os instrumentos normativos nos fóruns e entidades representativas da categoria profissional.

$\mathrm{O}$ equacionamento da questão não se restringe às ações profissionais isoladamente. Antes precisa contemplar a formação profissional, com análises críticas sobre a questão racial; a produção de conhecimento nos níveis de mestrado, doutorado e pós-doutorado; o combate ao racismo nas diversas instituições, públicas e privadas; a suspensão do cotidiano para a reflexão dos efeitos nocivos do racismo na sociedade brasileira e o retorno do sujeito à realidade, cada vez mais crítico; e uma interface urgente entre o Serviço Social e as outras áreas das Ciências Sociais, que acumularam ao longo de décadas conhecimentos teóricos riquíssimos acerca da questão racial no Brasil.

Finalmente, há que se ressaltar que passados 124 anos da abolição da escravatura, o "legado" da marginalização da população negra permanece naturalizado. Se defendemos que as relações sociais são datadas e historicamente construídas, faz-se urgente a ressignificação da trajetória histórica da população negra no interior da sociedade brasileira, escancarando as perversidades perpetradas contra esse grupo e a consequente desigualdade racial e social.

Por tudo o que foi exposto, não é mais tolerável na atualidade a falta de compromisso profissional coletivo em relação à questão racial, seja porque há um amplo debate na sociedade sobre a promoção da igualdade racial — ainda que historicamente os grupos dominantes continuem tentando desqualificar a luta coletiva - , seja porque o projeto ético-político profissional do Serviço Social, explicitado no Código de Ética de 1993, reconhece a liberdade como valor ético central, propõe a defesa intransigente dos direitos humanos, o empenho na eliminação de todas as formas de preconceito e a não discriminação como princípios éticos fundamentais.

É por isso que a humanidade só se propõe as tarefas que pode resolver, pois, se se considera mais atentamente, se chegará a conclusão de que a própria tarefa só aparece onde as condições materiais de sua solução já existem, ou, pelo menos, são captadas no processo do seu devir. (Marx, 1978, p. 130)

Recebido em 17/7/2012 - Aprovado em 11/3/2013 


\section{Referências bibliográficas}

AMMA-PSIQUE E NEGRITUDE QUILOMBHOJE. Gostando mais de nós mesmos: perguntas e respostas sobre a autoestima e questão racial. São Paulo: Gente, 1999.

. Identificação e abordagem do racismo institucional. Brasil, 2008.

BARROCO, M. L. S. Ética e Serviço Social: fundamentos ontológicos. 4. ed. São Paulo: Cortez, 2006.

CASHMORE, E. et al. Dicionário de relações étnicas e raciais. Tradução de Dinah Kleve. São Paulo: Selo Negro, 2000.

CHAUI, M. Brasil: mito fundador e sociedade autoritária. 7. ed. São Paulo: Fundação Perseu Abramo, 2007.

DFID/PNUD. Programa de combate ao racismo institucional no Brasil. Brasília: 2005.

GOMES, N. L. A mulher negra que vi de perto. Belo Horizonte: Mazza Edições, 1995.

GUIMARÃES, A. S. A. Racismo e antirracismo no Brasil. São Paulo: Editora 34, 1999.

HELLER, A. O cotidiano e a história. Rio de Janeiro: Paz e Terra, 1970.

IAMAMOTO M. V. O Serviço Social na contemporaneidade: trabalho e formação profissional. 2. ed. São Paulo: Cortez, 1999.

IANNI, O. A ideia de Brasil moderno. São Paulo: Brasiliense, 1992.

IRACI, N.; SOVIK, L. Diálogos contra o racismo. Rio de Janeiro: Instituto Brasileiro de Análises Sociais e Econômicas (Ibase), dez. 2004.

JACCOUDE, L. O combate ao racismo e à desigualdade: o desafio das políticas públicas de promoção da igualdade racial. In: THEODORO, M. (Org.). As políticas públicas e a desigualdade racial no Brasil: 120 anos após a abolição. Brasília: Ipea, 2008.

LOPES, F.; QUINTILIANO, R. Racismo institucional e o direito humano à saúde. Democracia Viva, Rio de Janeiro, n. 34. jan./mar. 2007. Disponível em: <http://www.ibase.br>. Acesso em: 10 jan. 2011.

MARX, K. Manuscritos econômico-filosóficos e outros textos escolhidos. 2. ed. Tradução de José Carlos Bruni et al. São Paulo: Abril Cultural, 1978.

MINAYO, M. C. S. O desafio do conhecimento: pesquisa qualitativa em saúde. São Paulo: Hucitec, 2002.

NETTO, J. P. Capitalismo monopolista e Serviço Social. 4. ed. São Paulo: Cortez, 2005. 
PAIXÃO, M.; CARVANO, L. M. (Orgs.). Relatório anual das desigualdades raciais 2007-2008. Rio de Janeiro: Garamond, 2008.

PINTO, E. A. O Serviço Social e a questão étnico-racial: um estudo de sua relação com usuários negros. São Paulo: Terceira Margem, 2003.

POLÍTICA NACIONAL DE SAÚDE INTEGRAL DA POPULAÇÃO NEGRA. Secretaria Especial de Políticas de Promoção da Igualdade Racial (Seppir). Brasília, 2007. Disponível em: <http://bvsms.saude.gov.br>. Acesso em: 25 nov. 2011.

ROMÃO, J. (Org.). História da educação do negro e outras histórias. Brasília: Ministério da Educação, Secretaria de Educação Continuada, Alfabetização e Diversidade, 2005.

SILVA, L. (Cuti). Cadernos Negros, São Paulo, n. 8, 1985.

; FERNANDES, M. D. Consciência negra do Brasil: os principais livros. Belo Horizonte: Mazza Edições, 2002.

THEODORO, M. (Org.). As politicas públicas e a desigualdade racial no Brasil: 120 anos após a abolição. Brasília: Ipea, 2008.

WAISELFISZ, J. J. Mapa da violência 2011: os jovens do Brasil. São Paulo: Instituto Sangari, 2011. Disponível em: <http://www.mapadaviolencia.org.br>. Acesso em: 20 fev. 2011. 